\title{
Pratique médicale - Expérience(s), philosophie, histoire
}

\section{Jean Martin}

Dr méd., membre de la rédaction

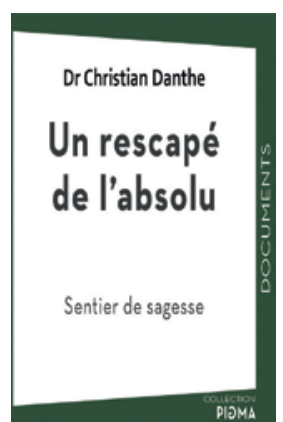

Christian Danthe

Un rescapé de l'absolu

Sentier de sagesse

Sainte-Croix: Editions Mon Village; 2018.

458 pages. $35 \mathrm{CHF}$.

ISBN 9782881943614

Le Dr Danthe a été médecin de famille à Vallorbe, dans le Jura vaudois, durant 35 ans. Il a toujours été intéressé par la réflexion et l'écriture et, à sa retraite, a repris dans son galetas sa "nécropole de papier», les cinq cents dossiers de ses patients décédés (sur une patientèle de six mille personnes) - il décrit le soin particulier qu'il accordait, lors d'une mort, à la «clôture» du dossier.

"Au fond de moi, j'ai conscience d'être habité par ceux que j’ai rencontrés. Je suis tissé des autres. Les métamorphoses de la vie active ont ébranlé mes certitudes au profit de représentations plus souples qui s'accordent avec mes équilibres nouveaux. C'est le souvenir des relations qui donne un sens à l'ensemble du cheminement.» "La mémoire est mouvement. Ce qui apparaissait futile a gagné en gravité. Le lourd s'est envolé. La migration des souvenirs a modifié les reliefs. La vie est transgression. Le timide a enfin osé son cri de colère, la servante s'est mise à danser [...] le prêtre est tombé amoureux. On contemple, on s'étonne, on doute.» "J'ai mis quelques dizaines d'années pour apprendre à m'émerveiller des ressources des personnes et à me débarrasser de mon tic spirituel qui consistait à juger, à normaliser, à obéir.»

$\mathrm{Au}$ cours de 38 chapitres, se basant sur les histoires qui lui ont été confiées, l'auteur développe des réflexions substantielles, marquées pas plusieurs lignes de force. D'abord son enfance dans un milieu évangélique très pratiquant. Il est aujourd'hui agnostique mais reste marqué par les Ecritures, souvent citées et commentées ainsi que parfois le Coran. Les philosophes grecs et romains sont aussi présents, avec ceux des Lumières et certains modernes - Trinh Xuan Thuan, Jacques Monod - mais aussi les shamanes. D'une manière qui pourra surprendre, il consacre cinq chapitres à la chose militaire: il a été lui-même officier et en parle; il évoque longuement deux patients qui ont été soldats à l'étranger et dont la trajectoire, les confidences et la vie au retour en Suisse l'ont marqué.
Parmi les thèmes débattus: les aléas de l'existence bien sûr, la mort et l'attitude devant elle, la mort fortuite/ imprévue, la croyance ou pas à une vie après la vie, la mort de l'animal compagnon, la dignité de la personne (discutant les doctrines utilitariste et/vs déontologique). Et aussi l'amour et la perte de l'aimé, l'enfant homosexuel (il y a quelques décennies), le sida, une migrante bohémienne et les risques de racisme, les expériences de mort imminente - et même des revenants rendant visite à un proche! Terminant par l'actualité, "les tentations messianiques» et transhumanistes - pour lesquelles il ne cache pas son peu d'attrait: «Deux cents ans de vie pour tous! Sans modification de l'âge de la retraite!» "Bienvenue sur le pont du paquebot vers un nouveau monde, celui de l'immortalité siliconée! On est arrivé à l'immortalité pour des méduses et des vers, l'homme suivra. Seule la mort violente ou volontaire aura encore droit de cité [on ne mourra plus de cause naturelle]. On disposera, à la dimension du monde, d'une médecine à deux vitesses ou trois ou cinq, avec leurs nouveaux empereurs et évêques, leurs soldats, leurs cours des miracles et l'extension illimitée de leurs déserts spirituels.»

Nos confrères ne sont pas rares qui ont, au terme de leur carrière, pris la plume pour parler de celle-ci. L'essai (en termes de rugby) de Christian Danthe est réussi. Ouvrage bien écrit, «buissonnant» comme disent les Vaudois, nourrissant par ses récits de compagnonnage avec ceux qui le consultent, chacun spécifique dans le colloque singulier. Dans ses dernières lignes: «Le moment venu, j'aimerais me retirer sur la pointe des pieds en disant: 'Ce n'était pas très bien, mais c'était bien. C'était imparfait mais c'était bien.'»

Pensant aux jeunes gens de vingt ans, naïfs à beaucoup d'égards, que lui et moi étions en entrant à la Faculté il y a un demi-siècle, pensant aussi aux étudiants d'aujourd'hui, pas forcément si différents malgré l'accès immédiat à "toutes les connaissances» par leur smartphone, j'ai envie de dire que Un rescapé de l'absolu est à recommander dans le cadre des «Medical Humanities» dont tout le monde dit la nécessité. Sans doute faut-il un peu de temps pour lire ces quelque 500 pages. Mais tentez la lecture, elle en vaut la peine. 